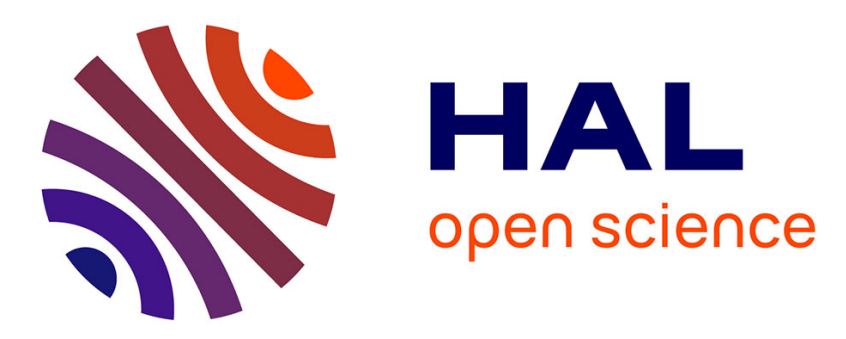

\title{
Stability evaluation of a railway timetable at station level
}

\author{
Xavier Delorme, Xavier Gandibleux, J. Rodriguez
}

\section{To cite this version:}

Xavier Delorme, Xavier Gandibleux, J. Rodriguez. Stability evaluation of a railway timetable at station level. European Journal of Operational Research, 2009, 195 (3), pp.780-790. 10.1016/j.ejor.2007.06.062 . hal-00506352

\section{HAL Id: hal-00506352 \\ https://hal.science/hal-00506352}

Submitted on 27 Jul 2010

HAL is a multi-disciplinary open access archive for the deposit and dissemination of scientific research documents, whether they are published or not. The documents may come from teaching and research institutions in France or abroad, or from public or private research centers.
L'archive ouverte pluridisciplinaire $\mathbf{H A L}$, est destinée au dépôt et à la diffusion de documents scientifiques de niveau recherche, publiés ou non, émanant des établissements d'enseignement et de recherche français ou étrangers, des laboratoires publics ou privés. 


\title{
Stability evaluation of a railway timetable at station level
}

\author{
Xavier DELORME ${ }^{\mathrm{a}}$ Xavier GANDIBLEUX ${ }^{\mathrm{b}}$ \\ Joaquín RODRIGUEZ ${ }^{\mathrm{c}}$
}

${ }^{a}$ Centre Génie Industriel et Informatique, École Nationale Supérieure des Mines de Saint-Etienne, 158 cours Fauriel, F42023 Saint-Etienne Cedex 2 - FRANCE Delorme@emse.fr

${ }^{\mathrm{b}}$ LINA, Université de Nantes, 2 rue de la Houssinière BP 92208, F44322 Nantes Cedex03 - FRANCE - Xavier.Gandibleux@univ-nantes.fr

'INRETS-ESTAS, 20 rue Élisée Reclus, F59650 Villeneuve d'Ascq - FRANCE Joaquin.Rodriguez@inrets.fr

\begin{abstract}
This research deals with a real-world planning problem in railway infrastructure operations. It is part of the RECIFE project, which seeks to develop a decision support software to help evaluate the capacity of a rail junction or station. To this end, the project is working on a timetable optimization model, as well as timetable evaluation modules. This paper presents a module for evaluating timetable stability, which uses an original method based on delay propagation and using shortest path problem resolution. A didactic example and a complete case study applying this method to the Pierrefitte-Gonesse junction are also presented.
\end{abstract}

Key words: Railway infrastructure capacity, Timetable stability, Shortest path, Multi-objective optimization

\section{Introduction}

This paper is an extended version of a previous article (Delorme et al., 2006). It focuses on railway infrastructure operations planning at the level of a rail junction or station (also called a node). In order to implement a rail transport supply strategy, tools able to identify the limits of an existing or future network, with one or more possible supply configurations, are needed. Such tools allow a decision-maker to evaluate the network limits, and must facilitate the detailed investigation of each infrastructure variant to enable its benefits to 
be assessed. This kind of careful analysis is crucial given the extremely high costs and the long-term implications of system modifications. It is especially important in certain complex junctions or stations where bottlenecks develop due to increasing traffic.

Usually, the capacity of a rail system component is assessed by measuring the maximum number of trains that can be operated on it within a certain unit of time. Analytical models can be used to measure the capacity $C$ of railway lines in a given direction. This capacity can be expressed theoretically as:

$$
C=\frac{u}{h}
$$

where $h$ is the minimum headway time between two successive trains and $u$ is the unit of time. The minimum headway time depends on the signaling system installed on the line being evaluated. More accurate analytical expressions can be used to include more rail system features (U.I.C., 1978). However, analytical models alone are not sufficient for measuring the junction or station capacity because the capacity of these nodes is not simply the sum of the capacity of the converging lines. In Florio and Mussone (1996), an analytical method is proposed for junctions and stations, but the authors concluded on the need of search tools to find good or optimal solutions. For this reason, junction capacity is determined by solving an optimization problem called the "Railway Infrastructure Saturation Problem" (RISP) (see Delorme et al., 2001). The RISP of a junction can be stated as follows:

Given the layout of a junction and a set of trains $T$, how many trains of $T$ can be routed through the junction within a certain unit of time, such that all safety constraints are satisfied and all practical operations conditions are respected?

As stated in U.I.C. (2004), the rail capacity is actually a multidimensional concept (see figure 1). So, although defining a saturated timetable is a large part of capacity evaluation, other elements often have to be considered, such as the feasibility of a given combination of trains. In addition to the number of trains, other objectives that must be considered include:

(1) the average speed of trains, which is directly linked with the stopping distance and thus may reduce the number of trains considerably,

(2) the uniformity of the train characteristics (e.g. type, speed), since a mixed traffic will limit the number of trains that can be scheduled, and

(3) the stability of the timetable which is the timetable's ability to absorb delays. 


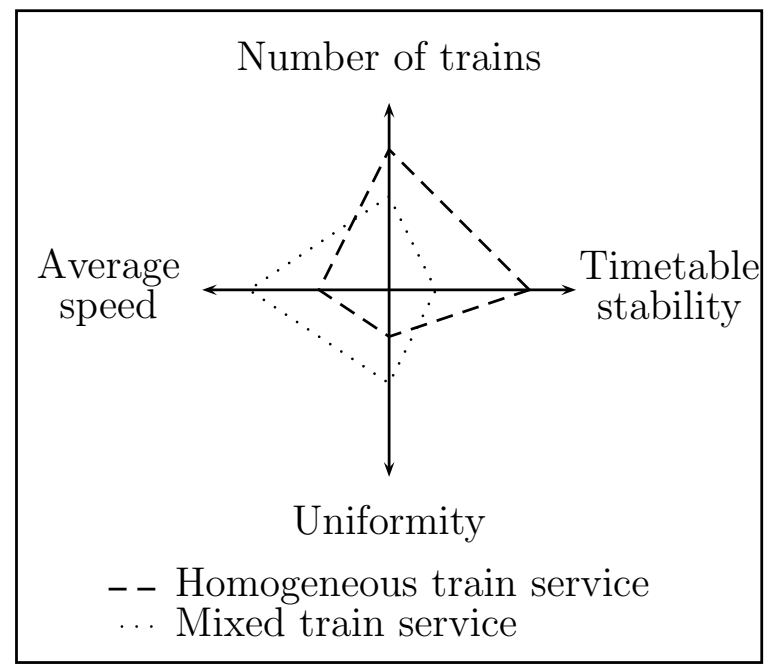

Fig. 1. Balancing the multiple dimensions of rail capacity

The project $\mathrm{RECIFE}^{1}$ was created to integrate theorectical research into a complete decision support software, which provides other functionalities in addition to the resolution of the saturation problem. An optimization model and several resolution algorithms, proposed to solve this capacity problem (Delorme, 2003), have already been integrated into the decision support software proposed by the RECIFE project. However, this software also include several analysis and visualization modules. The main functionalities provided in addition to the RISP problem resolution module are track layout visulization module, a Gantt diagram display module, and a timetable stability evaluation module. The software also includes a track layout editor to allow infrastructure modifications. These four modules will help decision-makers to evaluate the stability of the generated timetables and to determine the critical elements that must be modified to improve capacity and stability. Spatial and temporal aspects can be analyzed via a train run animation to the track layout (see figure 2), and various display parameters (e.g., zoom, marking elements, slowing down/speeding up) can be used to experiment freely with possible solutions. The Gantt diagram display module (see figure 3), which permits to identify the sections of a route with the heaviest traffic and shows the impact of the signalling system, also provides details about how the sequence of detection zones is used. With the graphics editor (see figure 4), railway infrastructure elements can be created and located along the track layout. The principal components include the track circuits, the points, the track crossings, the platforms, the maximum speed gauges and the signals that mark the limits between blocks. After identifying critical sections, the decision-makers can use this editor to define new infrastructure variants to evaluate.

1 The project RECIFE is a collaborative effort involving the French National Institute for Transport and Safety Research (INRETS), the École des Mines of Saint-Etienne, the University of Nantes and the French National Railway Company (SNCF), and up until the end of 2004, the University of Valenciennes. 


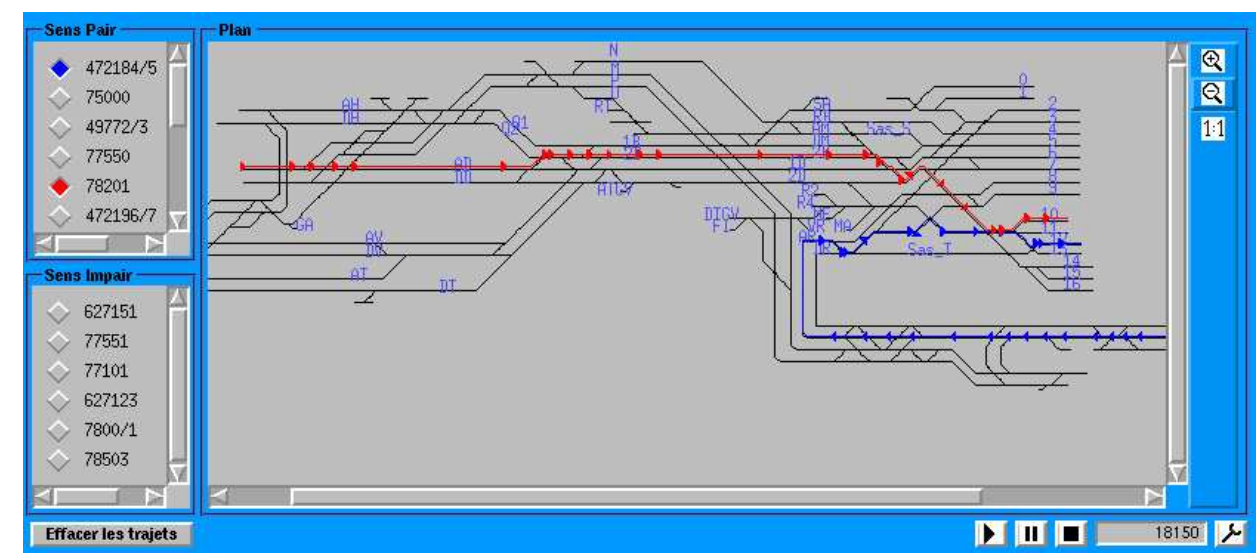

Fig. 2. Track layout timetable animation in RECIFE

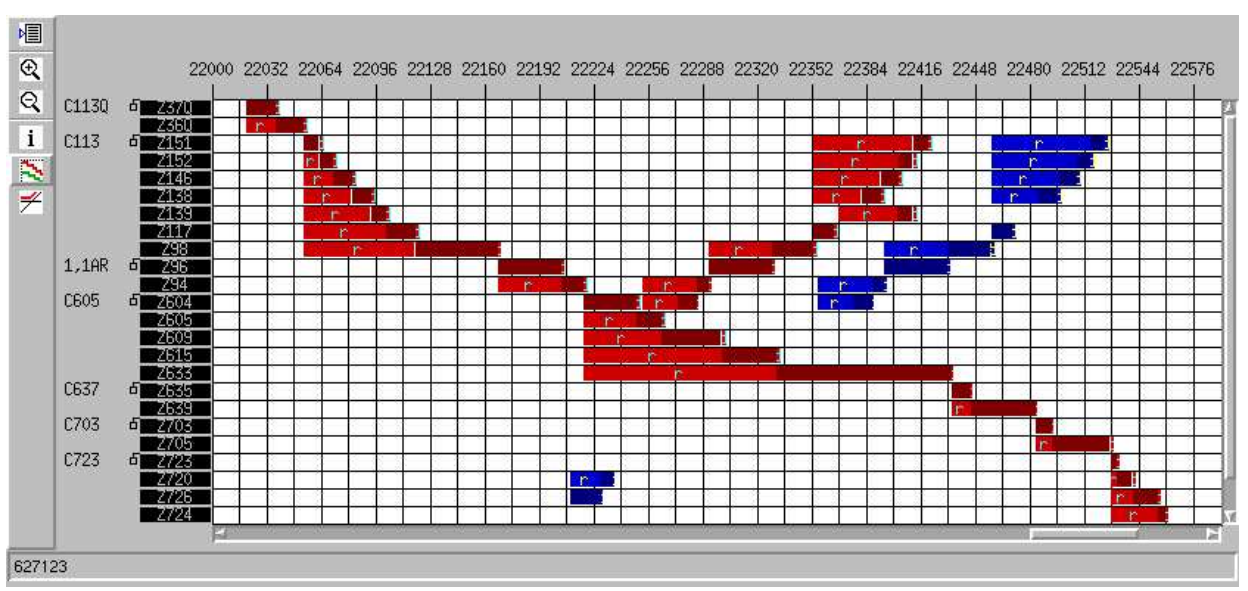

Fig. 3. Gantt chart timetable visualization in RECIFE

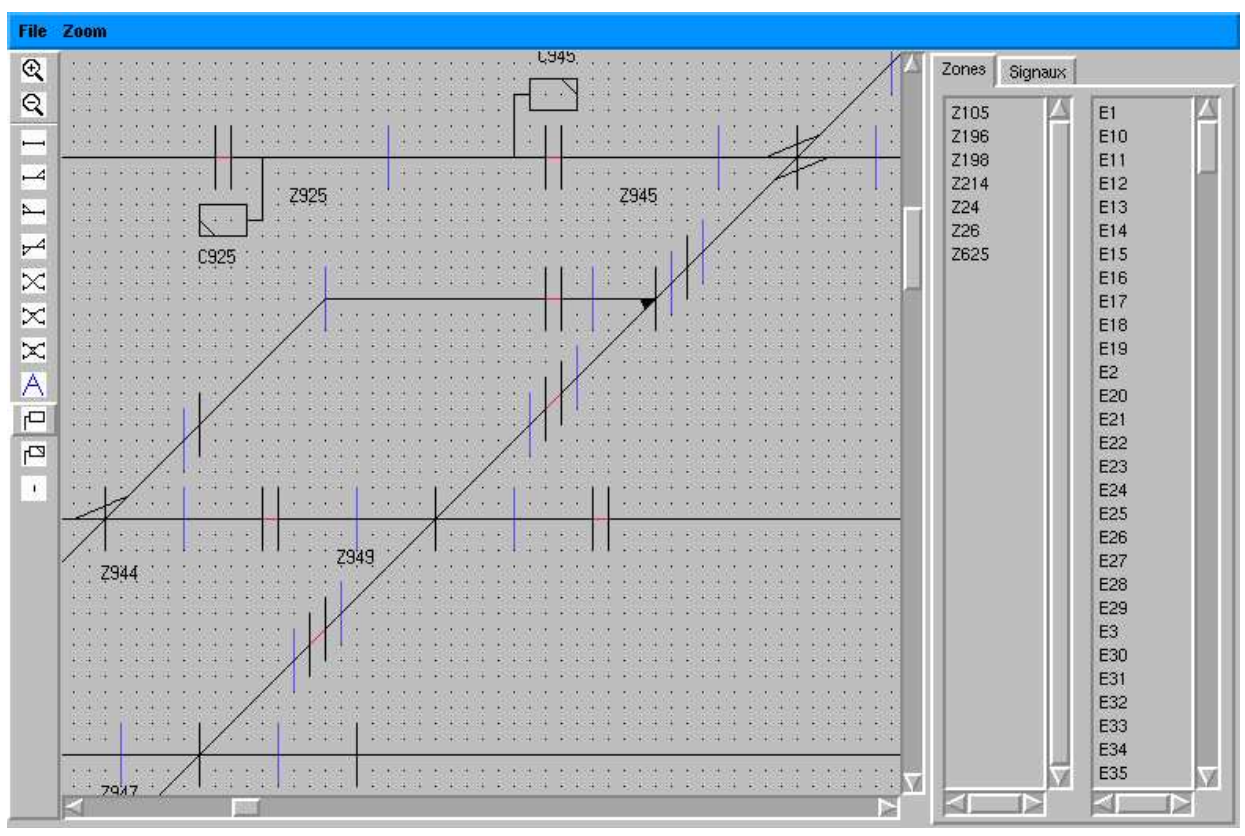

Fig. 4. Infrastructure layout editor in RECIFE 
The RECIFE decision support software described above is now fully operational and has been implemented at the Pierrefitte-Gonesse junction and the Lille-Flandres station in order to validate the principles and the proposed algorithms in real railway environments. In the future, this software could be embedded into a larger railway management system.

This paper describes the original method proposed to evaluate the stability of the generated timetables, dealing with the same variables defined in the optimization model under the same assumptions. This evaluation method, inspired by the know-how and the practical experience of railway managers, uses a model that propagates potential delays, which are computed by solving several shortest path problems. The objective is to determine the overall delay that results from an initial delay of any single train, and the direct or indirect effect of this delay on the other trains in the timetable.

The paper is organised as follows. The next section introduces the optimization model. Section 3 describes the stability evaluation model, and sections 4 and 5 , respectively, present a didactic example and a case study of this model used in a real rail infrastructure situation. Section 6 offers our conclusions based on a discussion of the issues raised earlier in the article.

\section{The railway infrastructure operation model}

This section briefly describes the optimization model used by the RECIFE project to assess rail infrastructure capacity. The complete version of this model was proposed by Delorme (2003). Many articles exist in the literature about the optimization of railway problems (see Bussieck et al., 1997; Cordeau et al., 1998), and various models have been proposed to solve many routing and scheduling problems for railways. However, few studies or softwares deal with analyzing infrastructure capacity. To date, only three studies have been published in this area, and they focus mainly on the capacity of global networks rather than on the capacity of a junction or a station:

- the project DONS (Design Of Network Schedules), initialy proposed by van den Berg and Odijk (1994), was developed by the Nederlandse Spoorwegen. The DONS subproject, CADANS (Lindner, 2000), deals with the global network, while the subproject STATIONS (Kroon et al., 1997; Zwaneveld, 1997; Zwaneveld et al., 1996, 2001) focuses on the station level.

- The Swiss project CAPRES, based on the research of Hachemane (1997), resulted in a commercial software (Curchod and Lucchini, 2001).

- The French project, DEMIURGE, is currently under development by the SNCF (Labouisse and Djellab, 2001). 
Like these three projects, the model presented in this paper uses a timetable saturation approach to evaluate capacity. A real timetable is produced using a construction method which builds a timetable that maximizes the number of train runs. This model is based on a list of trains, represented by binary variables, whose possible routes and arrival times have been pre-defined. Since the target is saturation at the node level, only the conflicts occurring within the studied area are taken into account. This approach makes sense because only the trains and times that are compatible with both the traffic demands and the extra-node requirements are relevant, which permits certain extra-node factors to be taken into account. The model seeks to optimize the timetable's feasability and saturation objectives, as well as the objective representing decision-maker preferences. The model's constraints formulation can cover a wide range of situations: several trains stopping at one platform, connecting trains, train coupling or uncoupling, and cyclic timetables, for example. Based on an incompatibility graph of the train-route assignments, the model is structured as a multi-objective combinatorial optimization set packing problem (SPP), a well known NP-hard problem. The highly detailed model allows practicable timetables to be generated for the infrastructures studied.

The following notations are used in the model:

$T$ : the set of trains.

Types: the set of different types of trains (e.g., passenger and freight).

$T_{\text {Feas }}$ : the subset of trains considered for the feasibility objective $\left(T_{\text {Feas }} \subseteq T\right)$.

$T_{\text {Sat }}$ : the subset of trains considered for the saturation objectives. $\left(T_{\text {Sat }}=\right.$ $\left.T \backslash T_{\text {Feas }}\right)$; this subset can be divided into $\mid$ Types $\mid$ subsets $T_{\text {Sat }}^{q}$ in order to study the uniformity dimension of rail capacity.

$R_{t}$ : the set of possible routes for a train $t \in T$.

$\Delta_{t}$ : the set of possible arrival times for a train $t \in T$.

$p_{t, r, \delta}$ : the pre-defined preference of decision-makers for the train $t \in T$ and its possible combination of route and arrival date $(r, \delta), r \in R_{t}, \delta \in \Delta_{t}$.

Inc: the set of all the incompatibilities between all the trains for all the possible combinations of routes and arrival dates; two incompatible trains selected in a timetable would produce a conflict and thus generate a delay.

Using binary decision variables $x_{t, r, \delta}$ with a value of 1 if the train $t$ is routed on the route $r$ with an arrival date $\delta$, and 0 if otherwise, the problem can be defined by the lexicographic model (2). The first objective $\left(z_{\text {Feas }}\right)$, corresponding to a feasibility problem, has top priority, followed by the other objectives 


$$
\left[\begin{array}{cl}
\text { lex max }\left(z_{\text {Feas }} \mid z_{\text {Sat }}^{q}, z_{\text {Pref }}\right) & \\
\text { sc } \quad z_{\text {Feas }}=\sum_{t \in T_{\text {Feas }}, r \in R_{t}, \delta \in \Delta_{t}} x_{t, r, \delta} & \\
z_{\text {Sat }}^{q}=\sum_{t \in T_{\text {Sat }}^{q}, r \in R_{t}, \delta \in \Delta_{t}} x_{t, r, \delta} & , \forall q \in \text { Types } \\
z_{\text {Pref }}=\sum_{t \in T, r \in R_{t}, \delta \in \Delta_{t}} p_{t, r, \delta} x_{t, r, \delta} & \\
\sum_{r \in R_{t}, \delta \in \Delta_{t}} x_{t, r, \delta} \leq 1 & , \forall t \in T \\
x_{t, r, \delta}+x_{t^{\prime}, r^{\prime}, \delta^{\prime}} \leq 1 & , \forall t, t^{\prime} \in T^{2} \\
& , \forall r, r^{\prime} \in R_{t} \times R_{t^{\prime}} \\
& , \forall \delta, \delta^{\prime} \in \Delta_{t} \times \Delta_{t^{\prime}} \\
& ,\left((t, r, \delta),\left(t^{\prime}, r^{\prime}, \delta^{\prime}\right)\right) \in \operatorname{Inc} \\
x_{t, r, \delta} \in\{0,1\} & , \forall t \in T, \forall r \in R_{t}, \delta \in \Delta_{t}
\end{array}\right]
$$

$\left(z_{\text {Sat }}^{q}, z_{\text {Pref }}\right)$ that all have equal priority, which leads to a multi-objective problem. The first constraint ensures that at most one route and one arrival date is chosen for each train. The second constraint prevents incompatible trains from being selected for the timetable.

\section{The stability evaluation model}

This section describes the approach used to analyze the stability of the timetable(s) obtained with the optimization model. Because several timetables with the same number of trains can be generated, stability evaluation can be used to distinguish between them.

Several methods have already been proposed to complete such an analysis, mainly for cyclic timetables. Many of these methods are based on Petri nets and Max-plus algebra (see Goverde, 2005, 2006, for recent work) and consider three types of stability evaluation:

(1) the time needed for the defined cyclic timetable to recover when a delay occurs,

(2) the permissible time margins for the different trains before they will delay any other trains, and

(3) the delay propagation statistics for various initial delay scenarios.

The first two types of evaluations are not appropriate for the problem under 
consideration, the first because timetables may be non-cyclic, and the second because time margins in saturated timetables are nearly null. On the other hand, delay propagation statistics can be provided by other methods, such as simulation (e.g. see Carey and Carville, 2000).

In addition to the above works on stability evaluation in existing timetables, de Kort et al. (2003) have proposed including stability as part of a probabilistic capacity evaluation model: this model is designed to process the maximum number of trains from unspecific timetables, while respecting a predefined stability threshold. Also, Vromans (2005) has recently considered stability optimization at the network level using a stochastic optimization model - which is, in fact, a large linear programming model - to optimize the average propagated delay of a cyclic timetable for a given set of disturbances. Finally, Engelhardt-Funke and Kolonko (2004) have presented a biobjective genetic algorithm, which achieves a compromise between investment cost and passenger waiting time by considering the propagation of random delays. However, this algorithm works only at the network level and does not take safety distances or capacity restrictions into account.

In this paper, we focus on stability evaluation in timetables based on delay propagation. As stated in Goverde (2005), two types of delay can be distinguished in railways. First, delays can be caused by a disruption within the process (e.g., time fluctuations due to technical or environmental conditions). Such delays, called primary delays or initial delays, do not depend on the timetable. Second, other delays can be caused by these primary delay due to train interactions (e.g., shared platforms or track sections, passenger connections, train coupling). Such delays, called secondary delays or knock-on delays, can sometimes be avoided, or at least limited, by certain timetable provisions.

Our stability model is based on calculating the secondary delays caused by a primary delay of one of the trains in the timetable. We assume that these secondary delays can be computed using the same route and scheduling selected for each train; only the arrival time can be updated to avoid conflicts. This assumption is justified by the practical difficulty of re-optimizing the timetable in real-time, but only makes sense with a short primary delay that is not expected to exceed the time needed by a train to go through the node. The evaluation corresponds then to the sum of all the secondary delays generated by a single primary delay, for each train in the timetable. Such stability evaluation has already been used at the SNCF, but computed by simulation rather than by our method. Since the result of such a stability evaluation is highly dependant on the value retained for the primary delay, several values should be considered making the stability evaluation itself a multi-objective problem. Figure 5 shows how this stability evaluation has been integrated into RECIFE, highlighting the strong links to the optimization model. 


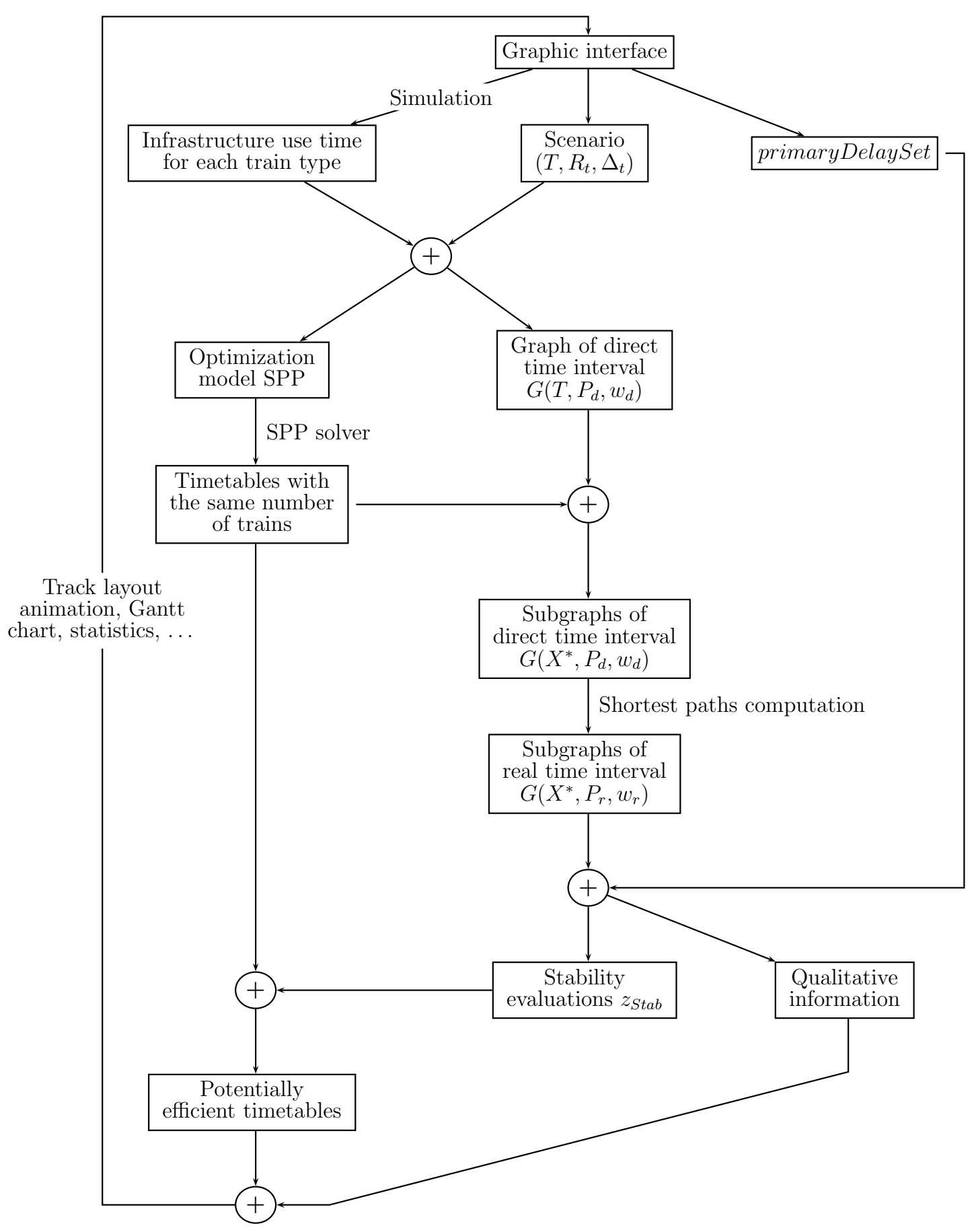

Fig. 5. Integration of the stability evaluation within RECIFE

The following notations are used to describe our stability evaluation method:

$X^{*}$ : the set of trains in the timetable to be evaluated (i.e., the variables selected in the corresponding saturation problem solution):

$$
X^{*}=\left\{(t, r, \delta), t \in T, r \in R_{t}, \delta \in \Delta_{t}, x_{t, r, \delta}=1\right\}
$$

primary Delay: the value considered for the primary delay, applied successively 
to each train $x \in X^{*}$.

$P_{d}$ : the set of potential direct conflicts between any couple of trains $x \in X^{*}$ :

$$
\begin{aligned}
& P_{d}=\left\{\left((t, r, \delta),\left(t^{\prime}, r^{\prime}, \delta^{\prime}\right)\right) \in X^{* 2}, t \neq t^{\prime},\right. \\
& \left.\exists \Delta>0,\left((t, r, \delta+\Delta),\left(t^{\prime}, r^{\prime}, \delta^{\prime}\right)\right) \in \text { Inc }\right\}
\end{aligned}
$$

$w_{d}: P_{d} \rightarrow \mathbb{N}$ : the direct time interval between the two trains (i.e., the largest possible delay value for the first train before generating a direct conflict with the second train).

$$
\begin{gathered}
w_{d}(e)=\max (d, \forall \Delta \\
\left.\forall\{1, \ldots, d\},\left((t, r, \delta+\Delta),\left(t^{\prime}, r^{\prime}, \delta^{\prime}\right)\right) \notin \text { Inc }\right), \\
\forall e=\left((t, r, \delta),\left(t^{\prime}, r^{\prime}, \delta^{\prime}\right)\right) \in P_{d}
\end{gathered}
$$

The whole set of secondary delays generated by a primary delay of any train in the timetable can be computed with the oriented and valued graph $G\left(X^{*}, P_{d}, w_{d}\right)$. On this graph, each node represents one train in the timetable. Each couple of nodes is linked by an oriented edge when a delay associated to the first node can delay the second, the minimal value of such a delay corresponding to the value of the edge (the function $w_{d}$ ). Once such a graph has been generated for the whole set of trains $T$, the subgraph corresponding to a particular timetable is easily obtained.

However, a train can be delayed either by a direct or indirect conflict, with the secondary delays of some trains generating other secondary delays in a snowball effect. Thus, the real time interval available between two trains, represented by two nodes $x 1$ and $x 2$ on the graph, corresponds to the maximal possible delay for train $x 1$ that will not generate, directly or indirectly, a delay for train $x 2$. The real time interval between each couple of trains can be obtained by computing the shortest path between the two corresponding nodes (which can be easily done in polynomial time) and represented by a graph $G\left(X^{*}, P_{r}, w_{r}\right)$ where:

$P_{r}$ : couples of train with a path in $G\left(X^{*}, P_{d}, w_{d}\right)$.

$w_{r}: P_{r} \rightarrow \mathbb{N}:$ the shortest path between each couple of nodes in $G\left(X^{*}, P_{d}, w_{d}\right)$.

Once this time interval is known, the secondary delay for train $x 2$ generated by any primary delay of train $x 1$ on the can be computed. Indeed, the graph $G\left(X^{*}, P_{r}, w_{r}\right)$ depends only on the timetable and can be computed only once whatever the number of primary delay values that might be considered. The stability evaluation for the set primaryDelaySet containing the primary delay values considered can be deduced from all these secondary delays, as follows: 


$$
\begin{aligned}
& z_{\text {Stab }}(\text { primaryDelay })=\sum_{x 1 \in X^{*}}\left(\sum_{x 2 \in X^{*} \backslash\{x 1\}} \max \left(0, \text { primaryDelay }-w_{r}(x 1, x 2)\right)\right), \\
& \forall \text { primaryDelay } \in \text { primaryDelaySet }
\end{aligned}
$$

This approach can be compared to the one proposed recently by Goverde (2006), which is based on critical path searches in the timed event graph associated with the max-plus model considered.

As indicated above, this is a multi-objective evaluation. The main definitions considered are introduced below. Let $y_{1}$ and $y_{2}$ be two timetables. The stability evaluation for all primary delays $k \in$ PrimaryDelaySet considered is noted $z_{\text {Stab }}^{k}\left(y_{1}\right) . y_{1}$ dominates $y_{2}$ in the sense of Pareto dominance if and only if $z_{\text {Stab }}^{k}\left(y_{1}\right) \leq z_{\text {Stab }}^{k}\left(y_{2}\right), \forall k \in$ PrimaryDelaySet with $z_{\text {Stab }}^{k}\left(y_{1}\right)<z_{\text {Stab }}^{k}\left(y_{2}\right)$ for some $k$. Considering the set $Y$ containing all the feasible timetables with the same number of trains, a timetable is considered to be efficient if there is no $y^{\prime} \in Y$ such that $y^{\prime}$ dominates $y$. This means that no timetable is at least as good as $y$ for all primary delays, and none is strictly better for at least one primary delay. The set of efficient solutions $Y_{E} \subseteq Y$ represents a frontier, or trade-off surface. However, since the whole $Y$ set is not evaluated, but only a subset $Y^{\prime} \subseteq Y$ generated from the optimization model, the efficient set $Y_{E}$ cannot be determined. Instead, the set of potentially efficient timetables $Y_{P E} \subseteq Y^{\prime}$ is considered, such that no timetable in $Y_{P E}$ is dominated by a timetable from $Y^{\prime}$. Usually, decision-makers can limit their investigation to the potentially efficient timetables and look for the best compromise among them.

In addition to the quantitative evaluation provided by these sums, the graph $G\left(X^{*}, P_{r}, w_{r}\right)$ also permits a qualitative evaluation of a particular timetable, thus allowing the decision-makers to determine which are the critical trains and/or the blocking ressources.

It should also be noted that, though this stability evaluation method was developed as part of the RECIFE project and thus was designed to deal with the same variables and assumptions as the RECIFE optimization model, the method can be used independently to evaluate the stability of timetables provided by other approaches. Thus, this method permits the stability evaluation of any real timetable, saturated or not.

\section{An example of stability evaluation}

This section presents a didactic example of the stability evaluation method presented above. The example is based on the Pierrefitte-Gonesse node (Figure 
6), located north of Paris. Three main kinds of trains run through this node in both directions:

- TGV (High speed trains) between Paris and the High Speed Line (HSL),

- Inter-City trains between Paris and Chantilly, and

- Freight trains between Chantilly and the Grande Ceinture which cuts across the TGV routes.

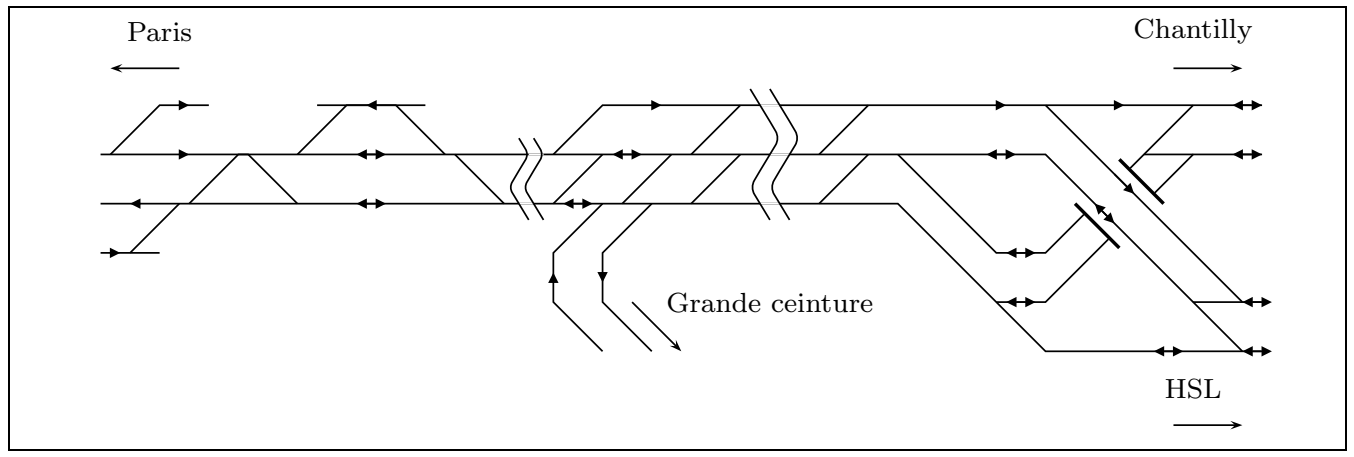

Fig. 6. Railway track map of the Pierrefitte-Gonesse node

Consider an instance problem with a set $T$ composed of six trains: two TGV, two Inter-City trains, and two Freight trains. Each train has only one possible arrival date and the interval between the first and the last arrival date is equal to 450 seconds. The set Inc has been computed using the data provided by the railway simulator SISYFE (Fontaine and Gauyacq, 2001).

The resulting optimization model for this problem is a set packing problem with 36 variables. The heuristic proposed by Delorme et al. (2004) was chosen to solve this SPP, first, because it generates several solutions with the same objective value, which is necessary to compare their stability, and, second, because this is one of the best published heuristics for the SPP according to the recent paper of Alidaee et al. (2007).

This heuristic, based on the GRASP metaheuristic proposed by Féo and Resende (1989) (see Resende and Ribeiro, 2002, for a recent overview), is derived from the classic GRASP scheme (i.e., a multistart greedy algorithm coupled with a local search) enhanced by three advanced components: automatic parameters tuning (reactive GRASP), a learning process and a path-relinking strategy.

The best solutions obtained with this heuristic contain five trains, which actually corresponds to the optimal solution for this problem, no solution with six trains being feasible due to the possible arrival time of each train (either an inter-city train or a freight train is excluded from the timetable generated). Such exclusions frequently occur when some trains belong to a saturation list. Fifteen different timetables with five trains were generated by the heuristic, and the stability evaluation method can help decision-makers choose between 
the different timetables.

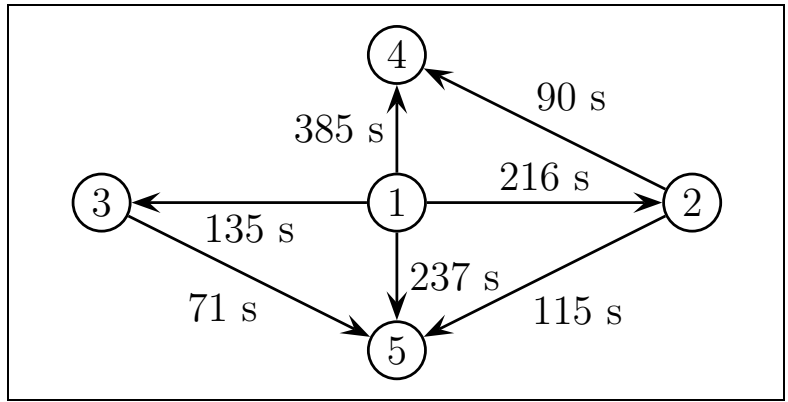

Fig. 7. Example of a graph $G\left(X^{*}, P_{d}, w_{d}\right)$

To compute the stability evaluation of the timetables, the graph $G\left(X^{*}, P_{d}, w_{d}\right)$ associated with each one must be generated. Figure 7 represents the graph obtained for one of the solutions. The five nodes correspond to the five trains routed, and the edges to the maximal delay before a conflict will occur. As the figure shows, a delay of train 1 longer than 216 seconds would delay train 2 , but any potential delay of train 4 would not delay train 3 since there is no edge from node 4 to 3 .

Once the graphs for each timetable have been generated, the time interval can be deduced by computing the shortest path between all couples of nodes in each graph. Figure 8 gives the shortest paths computed for the graph interval in the figure 7 : the new value for the edge $(1,4)$ (resp. $(1,5))$ is due to the delay propagated via the train 2 (resp. 3).

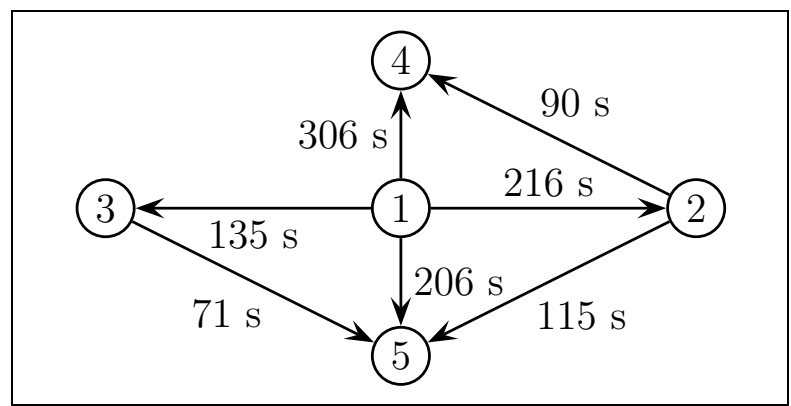

Fig. 8. Example of a graph $G\left(X^{*}, P_{r}, w_{r}\right)$ computed using shortest paths

At this point the different stability evaluations can be computed. Each evaluation is related to the value of a train's primary delay. Figure 9 presents the secondary delays generated by a primary delay of 180 seconds for the example described above. The edge from the node 1 to node 3 indicates that a primary delay of 180 seconds for train 1 would result in a delay of 45 seconds for train 3. Thus, the stability evaluation for this timetable given a primary delay of 180 seconds is equal to the sum of the secondary delays (i.e., 309 seconds). Moreover, as indicated in section 3, these secondary delays can be analyzed qualitatively: for a primary delay of 180 seconds, train 2 generates the most delays for the other trains (i.e., 155 seconds or $50 \%$ of the total); train 5 is the 
most delayed (i.e., 174 seconds or $56 \%$ ).

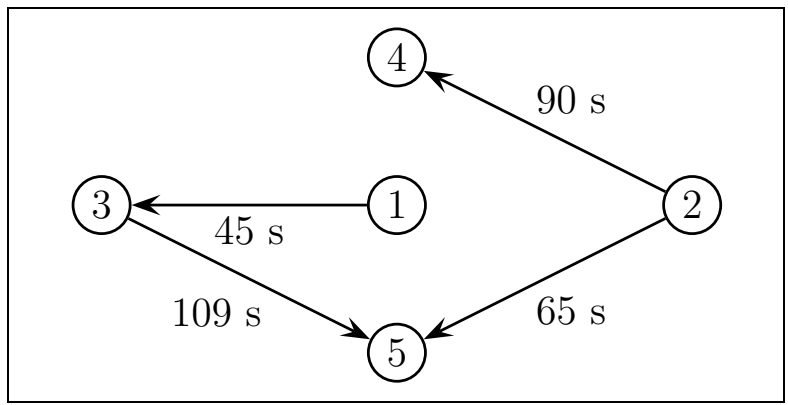

Fig. 9. Secondary delays generated for the example by a primary delay of $180 \mathrm{~s}$

The stability evaluation for the fifteen timetables was computed for a primary delay of 180 seconds and of 300 seconds. The results are reported in Figure 10. In this figure, each timetable is represented by a point with an abscissa equal to its stability evaluation for a primary delay of 180 seconds, and an ordinate equal to its stability evaluation for a primary delay of 300 seconds (the example illustrated in Figures 7-9 corresponds to solution 15). Solution 10 thus clearly seems to be the most stable timetable since it is the better on both evaluations, making it the only potentially efficient timetable. However, as is illustrated in section 5 , more than one potentially efficient timetable is usually obtained.

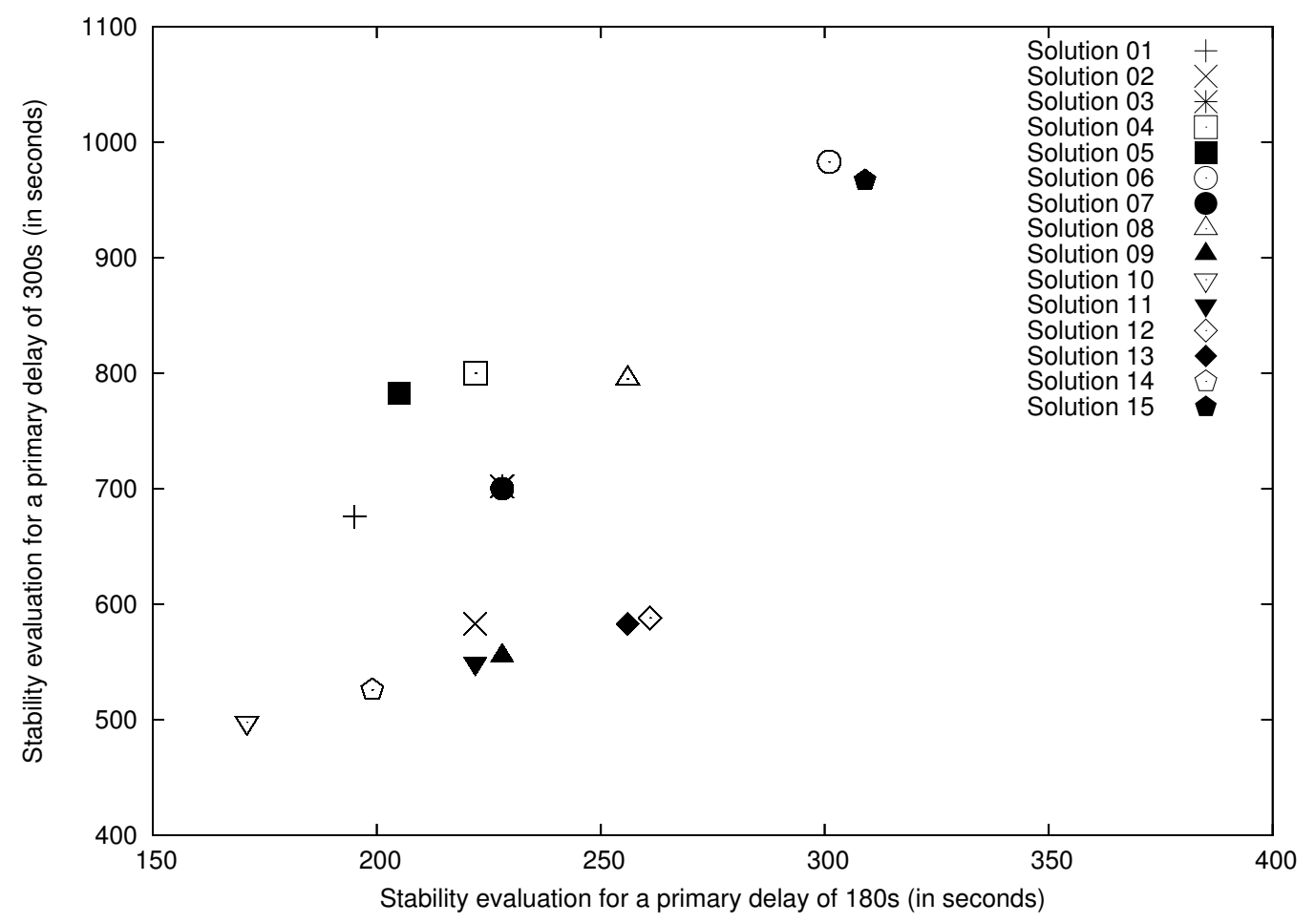

Fig. 10. Stability evaluation of the solutions to the example for the two primary delays 


\section{Case study}

This section presents a case study of our stability evaluation. The main characteristics of the six instances of the capacity problem considered are presented in table 1 . They correspond to six real sets of trains to be routed through the Pierrefitte-Gonesse junction $(125 \leq|T| \leq 200)$. Again, the set Inc was computed using data provided by the SISYFE simulator, and the resulting optimization models were solved using the same GRASP algorithm as in section 4. Obviously, the optimization model could also be solved with another heuristic or an exact algorithm, or the timetables could even be produced with another method. In order to keep a graphic display in the objective space of the stability evaluations, two primary delays (60s and 300s) were considered, but similar results were obtained with more than two primary delays.

\begin{tabular}{|l|r|r|r|lr|lr|}
\hline Instance & $|T|$ & SPP Variables & $\left|X^{*}\right|$ & $\begin{array}{l}\text { Number of } \\
\text { timetables with } \\
\left|X^{*}\right| \text { trains }\end{array}$ & $\begin{array}{l}\text { Number of po- } \\
\text { tentially efficient } \\
\text { timetables }\end{array}$ \\
\hline \hline 1 & 150 & 2,400 & 83 & 38 & 1 \\
\hline 2 & 125 & 2,683 & 87 & 36 & 2 \\
\hline 3 & 200 & 2,880 & 87 & 353 & 4 \\
\hline 4 & 157 & 3,210 & 86 & 500 & 1 \\
\hline 5 & 150 & 2,160 & 86 & 6 & 3 \\
\hline 6 & 130 & 2,503 & 102 & 30 & 2 \\
\hline
\end{tabular}

Table 1

Numerical characteristics of the instances

Depending on the instance considered, the number of different timetables with the same number of trains (i.e., the maximum number of trains found by GRASP) can be quite different. This can mean a large number of timetables to evaluate (e.g., instances 3 and 4) and thus a large number of shortest path problems to solve. However, the graphs are small (around 100 nodes), and very efficient algorithms for solving them exist. In fact, on an Pentium M with 1.8 $\mathrm{GHz}$, less than two minutes was necessary to compute the whole set of stability evaluations presented in this section. This CPU time is fully compatible with an interactive use for strategic studies. Moreover, despite the large number of timetables evaluated, the CPU time necessary for the stability evaluation is negligible compared to the time needed for the optimization phase (i.e., more than 20 minutes for each instance).

For all the instances considered, there is a very low number of potentially efficient timetables, so decision-makers can really focus on each of them. All the stability evaluations for each instance are displayed in Figure 11. In this 
figure, each timetable is represented by a point with an abscissa equal to its stability evaluation for a primary delay of 60 seconds, and an ordinate equal to its stability evaluation for a primary delay of 300 seconds. Please note that the number of points can be lower than the number of timetables since several timetables can have the same value for both stability evaluations.

Instance 1

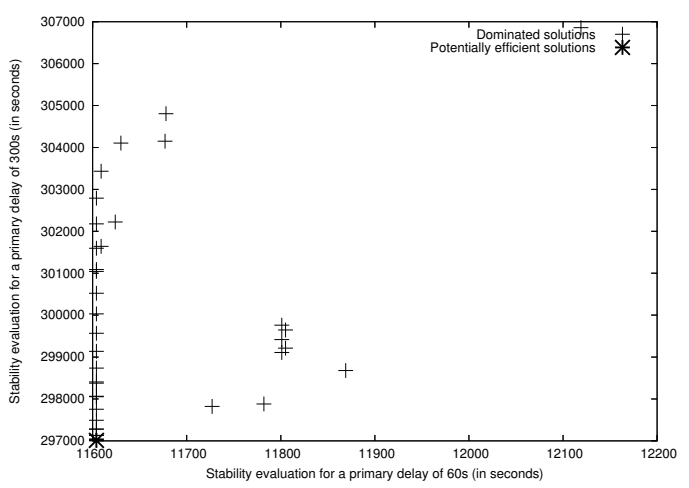

Instance 3

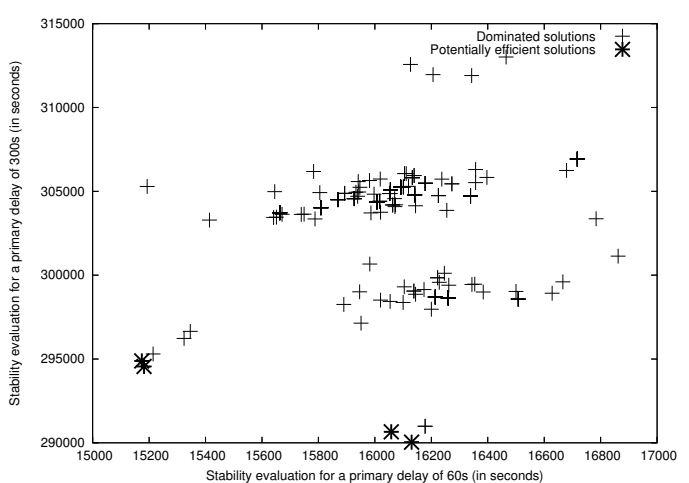

Instance 5

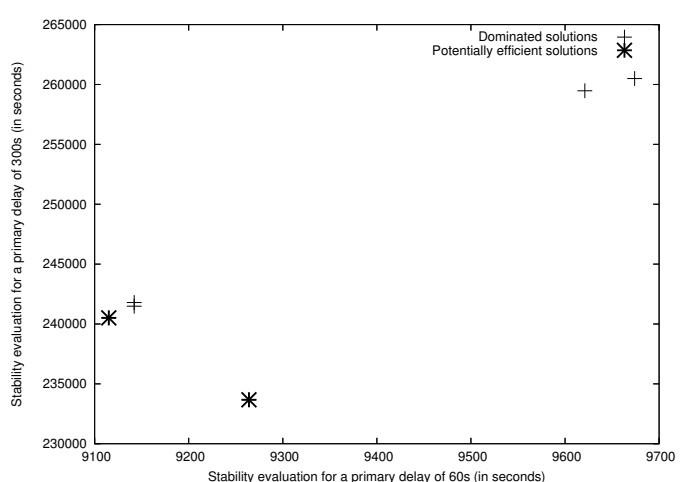

Instance 2

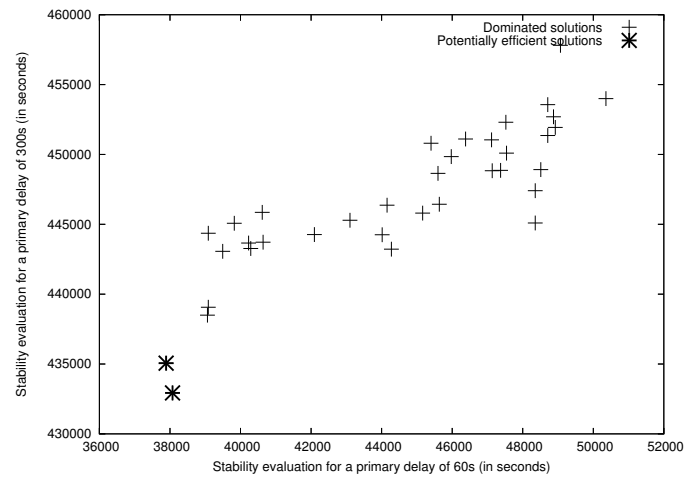

Instance 4

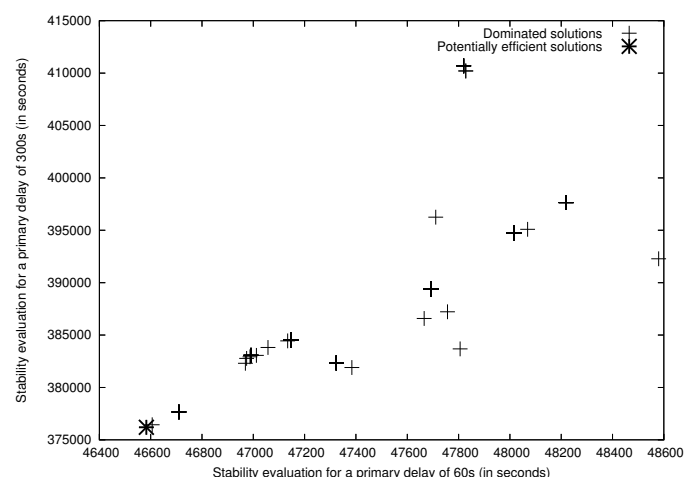

Instance 6

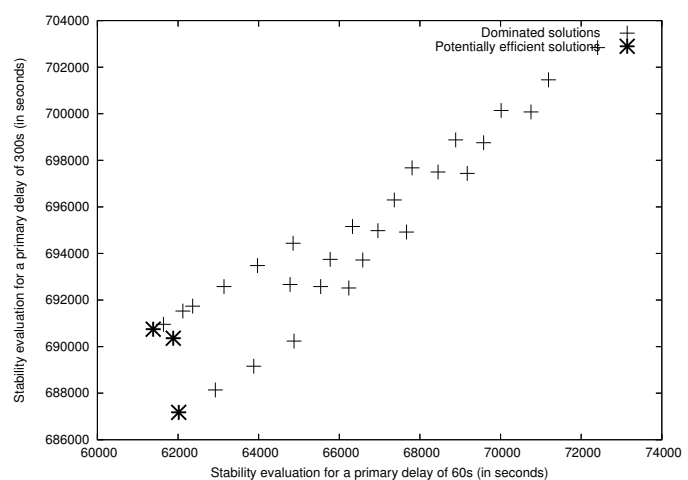

Fig. 11. Stability evaluation of the solutions for two primary delays

The stability values involved can be quite large since the timetables evaluated were saturated: for the instance 6, with 102 trains on the timetables, the largest value obtained is $702,838 \mathrm{~s}$, which means that the average value of the 
total secondary delays, generated by a primary delay of 300s for a single train, is $6,890 \mathrm{~s}$.

Instance 3 presents interesting results since, among the very large number of timetables evaluated, the potentially efficients timetables correspond to two quite different trade-offs for the impact of the two primary delays. For all the instances, including those with a very large number of timetables obtained with the same number of trains, the dominance relationship used as a filter appears strong enough to drastically reduce the number of solutions that must be examined.

Nevertheless, looking at the stability evaluation for each primary delay independently, it is interesting to note that the stability evaluation gap between the best and worst timetables can be very large, up to $32.9 \%$ (the mean and maximal gap are reported in table 2 for each instance and for each primary delay). Only instance 1 has a small gap between the best and the mean value (less than 1\%), and this is true for both stability evaluations. However, since there is only one potentially efficient timetable for this instance, the gap observed for the two stability evaluations is obtained by the same timetable.

Thus, it appears that choosing one of the potentially efficient timetables instead of a random one can yield significant gains in terms of stability. These results are very promising since the gains were obtained on saturated instances which yield timetable solutions whose stability is known to be difficult to improve. In addition, the results were obtained by just evaluating the available timetables without optimizing for stability.

Table 2

\begin{tabular}{|l|r|r|r|r|}
\hline \multirow{2}{*}{ Instance } & \multicolumn{2}{|c|}{$\begin{array}{l}\text { Stability evaluation } \\
\text { gap for a primary } \\
\text { delay of 60s }\end{array}$} & \multicolumn{2}{l|}{$\begin{array}{l}\text { Stability evaluation } \\
\text { gap for a primary } \\
\text { delay of 300s }\end{array}$} \\
\cline { 2 - 5 } & Mean & Maximal & Mean & Maximal \\
\hline 1 & $0.52 \%$ & $4.44 \%$ & $0.95 \%$ & $3.32 \%$ \\
2 & $17.48 \%$ & $32.90 \%$ & $3.20 \%$ & $5.75 \%$ \\
3 & $5.94 \%$ & $11.12 \%$ & $4.68 \%$ & $7.92 \%$ \\
4 & $2.02 \%$ & $4.29 \%$ & $3.21 \%$ & $9.17 \%$ \\
5 & $2.32 \%$ & $6.13 \%$ & $5.38 \%$ & $11.48 \%$ \\
6 & $7.55 \%$ & $17.96 \%$ & $1.05 \%$ & $2.28 \%$ \\
\hline
\end{tabular}

Stability evaluation gap 


\section{Conclusion}

In this paper, a new model for evaluating the stability of railway timetables was presented. Based on a delay propagation method, this evaluation is obtained by computing shortest path on a graph. The evaluation also matches the indicator used daily by our railway partner. To the best of our knowledge, this is the first multi-objective stability evaluation method.

The case study presented demonstrated the method's potential for producing significant gain in terms of stability, even without optimizing this dimension. The results obtained highlight the importance of a multi-objective stability evaluation capable of taking several primary delays into account.

Such a stability analysis can thus facilitate the choice between several timetables in a decision support software designed to assess the capacity of a junction or a station. For a particular timetable, studying the distribution of the secondary delays among the trains on a timetable can help decision-makers to determine the critical trains and/or the blocking ressources. Obviously, other delay propagation indicators could be generated with this model.

Future research will focus on developing a model for optimizing stability instead of just evaluating it, or on integrating stability evaluation into a multiobjective heuristic scheme as is done in Engelhardt-Funke and Kolonko (2004). In addition to improving the timetable stability, this integration would also allow the trade-off frontier between stability and the number of trains to be studied.

\section{References}

Alidaee, B., Kochenberger, G., Lewis, K., Lewis, M., Wang, H., 2007. A new approach for modeling and solving set packing problems. European Journal of Operational Research(In press).

Bussieck, M. R., Winter, T., Zimmermann, U. T., 1997. Discrete optimization in public rail transport. Mathematical programming 79, 415-444.

Carey, M., Carville, S., 2000. Testing schedule performance and reliability for train stations. Journal of the Operational Research Society 51 (6), 666-682.

Cordeau, J.-F., Toth, P., Vigo, D., 1998. A survey of optimization models for train routing and scheduling. Transportation Science 32 (4), 380-404.

Curchod, A., Lucchini, L., 2001. CAPRES: description générale du modèle. Tech. Rep. 788/5_f, LITEP, Lausanne, (In french).

de Kort, A. F., Heidergott, B., Ayhan, H., 2003. A probabilistic (max, +) approach for determining railway infrastructure capacity. European Journal of Operational Research 148, 644-661. 
Delorme, X., 2003. Modélisation et résolution de problèmes liés à l'exploitation d'infrastructures ferroviaires. Phd thesis, Université de Valenciennes et du Hainaut Cambrésis, Valenciennes, France, (In french).

Delorme, X., Gandibleux, X., Rodriguez, J., 2004. GRASP for set packing problems. European Journal of Operational Research 153 (3), 564-580.

Delorme, X., Gandibleux, X., Rodriguez, J., 2006. Stability evaluation of a railway timetable at station level. In: Dolgui, A., Morel, G., Pereira, C. (Eds.), Information Control Problems In Manufacturing 2006: A Proceedings volume from the 12th IFAC International Symposium (INCOM'06), St Etienne, France, 17-19 May 2006. Vol. 3. Elsevier Science, pp. 379-384.

Delorme, X., Rodriguez, J., Gandibleux, X., 2001. Heuristics for railway infrastructure saturation. In: Baresi, L., Lévy, J.-J., Mayr, R., Pezzè, M., Taentzer, G., Zaroliagis, C. (Eds.), ICALP 2001. Vol. 50 of Electronic Notes in Theoretical Computer Science. Elsevier Science, pp. 41-55.

Engelhardt-Funke, O., Kolonko, M., 2004. Analysing stability and investments in railway networks using advanced evolutionary algorithms. International Transactions in Operational Research (11), 381-394.

Féo, T. A., Resende, M. G., 1989. A probabilistic heuristic for a computationally difficult set covering problem. Operations Research Letters 8, 67-71.

Florio, L., Mussone, L., 1996. A method of capacity computation for complex railways systems. In: D., H., Oum, K. J. T. H. (Eds.), World Transport Research, selected proceedings of 7 th World Conference on Transport Research (WCTR). Vol. 4. Elsevier Science, pp. 275-291.

Fontaine, M., Gauyacq, D., 2001. SISYFE : a toolbox to simulate the railway network functioning for many purposes. some cases of application. In: Proceedings CDROM of the 5th World Congress on Railway Research (WCRR'2001).

Goverde, R. M., 2005. Punctuality of railway operations and timetable stability analysis. Phd thesis, Delft University of Technology, TRAIL research school, Delft, Netherlands.

Goverde, R. M., 2006. Railway timetable stability analysis using max-plus system theory. Transportation Research Part B(In press).

Hachemane, P., 1997. évaluation de la capacité de réseaux ferroviaires. Phd thesis, École Polytechnique Fédérale de Lausanne, Lausanne, Suisse, (In french).

Kroon, L. G., Romeijn, H. E., Zwaneveld, P. J., 1997. Routing trains through railway stations : complexity issues. European Journal of Operational Research 98, 485-498.

Labouisse, V., Djellab, H., 2001. DEMIURGE: a tool for the optimisation and the capacity assessment for railway infrastructure. In: Proceedings CDROM of the 5th World Congress on Railway Research (WCRR'2001).

Lindner, T., 2000. Train schedule optimization in public rail transport. Phd thesis, Fachbereich für Mathematik und Informatik der Technischen Universität Braunschweig, Braunschweig, Germany.

Resende, M. G., Ribeiro, C. C., 2002. Greedy randomized adaptive search 
procedures. In: Glover, F., Kochenberger, G. (Eds.), Handbook in Metaheuristics. Kluwer academic publishers, Boston, pp. 219-249.

U.I.C., 1978. Leaflet 405r. Tech. rep., UIC.

U.I.C., 2004. Leaflet 406r. Tech. rep., UIC.

van den Berg, J., Odijk, M. A., 1994. DONS : computer aided design of regular service timetables. In: Murphy, T., Mellitt, B., Brebbia, C., Sciutto, G., Sone, S. (Eds.), Computers in Railway IV (COMPRAIL 94). Vol. 2. Computational Mechanics Publications, Southampton Boston, pp. 109-115.

Vromans, M. J., 2005. Reliability of railway systems. Phd thesis, Erasmus University Rotterdam, TRAIL research school, Rotterdam, Netherlands.

Zwaneveld, P. J., 1997. Railway planning - routing of trains and allocation of passenger lines. Phd thesis, Rotterdam school of management, TRAIL research school, Rotterdam, Netherlands.

Zwaneveld, P. J., Kroon, L. G., Romeijn, H. E., Salomon, M., Dauzère-Pérès, S., Van Hoesel, S. P., Ambergen, H. W., 1996. Routing trains through railway stations : Model formulation and algorithms. Transportation Science 30 (3), 181-194.

Zwaneveld, P. J., Kroon, L. G., Van Hoesel, S. P., 2001. Routing trains through a railway station based on a node packing model. European Journal of Operational Research 128, 14-33. 